\title{
Transaction
}

\section{Evaluation of Proton Exchange Membrane Reinforced with Fluoroplastic Fiber Sheet for Fuel Cell}

\author{
Masao Sudoh $^{* 1}$, Keiichi Okajima ${ }^{* 1}$, Ippei Osaki ${ }^{* 1}$, Hajime Tsuda $^{* 2}$ and Takanori Suzuki ${ }^{* 2}$ \\ ${ }^{* 1}$ Faculty of Engineering, Shizuoka University, 3-5-1 Johoku, Hamamatsu, 432-8561, Japan \\ ${ }^{* 2}$ Tomoegawa Paper Co., Ltd., 3-1 Mochimune, Shizuoka, 421-0912, Japan
}

\begin{abstract}
Ion exchange membranes for fuel cell are expected to become thinner in order to reduce the membrane resistance. On the other hand, a thinner membrane has a weaker mechanical strength. The novel proton-exchange membranes were prepared by reinforcing with two kinds of $100 \%$ PTFE fiber sheets, which were fabricated by a papermaking method with or without uniaxially stretching as the core for a reinforced membrane. The stress, the strain, water content, ion exchange capacity and ionic conductivity were measured for different membranes. By pre-treating the PTFE sheet at $320^{\circ} \mathrm{C}$ and hot-pressing the membrane at $140{ }^{\circ} \mathrm{C}$, a strength of $27 \mathrm{MPa}$ was obtained for the membrane reinforced with a PTFE sheet in the machine direction (MD) and $21 \mathrm{MPa}$ in the transverse direction (TD). The tensile yield stress was almost the same as that of Nafion 112 in both directions. The water content and proton conductivity of the membrane reinforced with the PTFE sheet decreased to less than $28.3 \%$ and $20 \%$ when compared to that of Nafion112, respectively. The obtained ion exchange capacity was $0.89 \mathrm{~mol} / \mathrm{kg}$-dry.
\end{abstract}

(Received 16 June, 2002; Accepted 26 March, 2003)

\section{Introduction}

Among the various types of fuel cells, the polymer electrolyte fuel cell (PEFC) has the characteristics of low temperature operation $\left(70-90{ }^{\circ} \mathrm{C}\right)$ and high power density. The PEFC was invented at General Electric (GE) in 1955 and developed for the U.S. Gemini space program beginning in 1962 [1]. Although the early PEFC used hydrocarbon-based polymers, the perfluorosulfonic-acid membranes, such as Nafion ${ }^{\circledR}$, became the mainstream for PEFCs due to their greater stability in a fuel cell environment [2]. The following reactions take place in the anode and the cathode, respectively.

$\begin{array}{ll}\text { Anode: } & \mathrm{H}_{2} \rightarrow 2 \mathrm{H}^{+}+2 \mathrm{e}^{-} \\ \text {Cathode: } & 1 / 2 \mathrm{O}_{2}+2 \mathrm{H}^{+}+2 \mathrm{e}^{-} \rightarrow \mathrm{H}_{2} \mathrm{O}\end{array}$

The product of water vapor in the cathode diffuses backward through a polymer electrolyte membrane (PEM) to the anode, then the humidity of the membrane is supposed to be maintained during current generation.

The thickness of the PEM for the fuel cell is $200 \mu \mathrm{m}$ with swelling. The voltage of the cell declines due to the membrane resistance. When the membrane becomes dry, the proton conductivity of the membrane is interrupted.
Water management is a problem for fuel cells. Ion transport is influenced by the water content [3]. The membrane thickness and humidification conditions are the most significant variables for the PEFC. They significantly affect the performance of the fuel cell [4]. In our previous study, a thin grafted-membrane prepared by low temperature plasma polymerization had a resistivity lower than that of Nafion 117 [5]. Thin membranes with a thickness of $50 \mu \mathrm{m}$ or less have been recently required by many PEFC developers, but a thin plain membrane has a weak mechanical strength. Therefore, membranes need to be reinforced by materials such as the PTFE fabric [6]. In the present study, Poly(tetrafluoroethylene) (PTFE) or Poly(vinylidene fluoride) (PVDF) were considered as candidates for the support. PVDF has a melting point starting at $155^{\circ} \mathrm{C}$ and has a low hydrophobic property in comparison with PTFE. However, PVDF is not as strong as PTFE, and it was reported that the pore structure was affected during annealing above $120^{\circ} \mathrm{C}$ [7]. Meanwhile, PTFE is stable up to $260{ }^{\circ} \mathrm{C}$ and shows good chemical stability. Although PTFE has a hydrophobic property, its stability is desirable for the reinforced thin electrolyte membrane because of its high tensile strength. Thus, PTFE was selected as the support material.

In the development of reinforced membranes, the ion 
exchange membrane reinforced with a porous PTFE film has been reported [8]. The mechanical characteristics and dimensional stabilities were improved, but membrane resistance was not sufficiently reduced. Yoshitake et al. reported that the reinforced Flemion ${ }^{\mathbb{}}$-fibril membrane had improved mechanical properties [9]. The tensile yield stress was not sufficient, though the breaking stress with tensile strain was improved.

In a previous study, we reported a PTFE fiber sheet fabricated by sintering and removal of a self-adhesion material after mixing of the PTFE fibers with a self-adhesion material $[10,11]$. The bonding points on a PTFE sheet are sufficiently formed by sintering, and an improvement in the tensile yield stress of a reinforced PEM is expected. The objective of this study is to prepare novel membranes reinforced with two kinds of PTFE fiber sheets and a Nafion ionomer solution, and then evaluate the properties of membrane such as its strength as a function of the strain, water content, ion exchange capacity and proton conductivity.

\section{Experimental}

\subsection{PN membranes preparation}

Two kinds of $100 \%$ PTFE fiber sheets were prepared by a papermaking method with or without uniaxially stretching as the core for a reinforced PEM $[10,11]$. The PTFE fibers were uniformly dispersed into water with viscose to form a sheet. It was then sintered above the melting point of PTFE to bond the fibers together and eliminate the viscose and impurities. The sheet of fibers was uniformly flat and porous, and the uniaxially stretched sheet was drawn lengthwise on a single axle. Both sheets had a $20 \mu \mathrm{m}$ thickness. Afterwards, the sheets were sintered again to increase their strength in a muffle furnace for $30 \mathrm{~min}$ at 280 $340^{\circ} \mathrm{C}$ as pre-treatment for the PEM preparation [12].

The ordinary sheet and the uniaxially stretched sheet were then treated by boiling and ultrasonic cleaning. After deaeration in methanol (99\%), the PTFE sheets were impregnated in Nafion solution $(5 \mathrm{wt} \%)$ and dried at room temperature for two days. The heat treatment was then carried out using a hot press machine. A membrane thickness of $50 \mu \mathrm{m}$ was obtained. The membranes reinforced with the ordinary sheet and uniaxially stretched sheet were called PN1 and PN2, respectively. The content of PTFE in the PN1 membrane was $28.2 \%$ and in the PN2 membrane, it was $27.3 \%$.

For preparation of the recast membrane, a Nafion solution $\left(5 \mathrm{wt} \%\right.$ ) was cast onto a Teflon ${ }^{8}$ petri dish, and dried at room temperature for two days. A heat treatment was then carried out using a hot press machine. A $50 \mu \mathrm{m}$ thick membrane was obtained.

\subsection{The measurement of strength and strain}

The membrane strength was measured with a tensile tester (Shimadzu AG5000D). The distance between chucks of the samples was $10 \mathrm{~mm}$ and the tension rate was $50 \mathrm{~mm} / \mathrm{s}$. The measurement was carried out in both the machine and transverse directions, which were abbreviated MD and TD, respectively, at $20^{\circ} \mathrm{C}$ and $65 \%$ humidity.

\subsection{Ion exchange capacity}

The ion exchange capacity of the membranes was obtained using a common procedure. A membrane, which had its dry weight measured, was soaked in 1 $\mathrm{kmol} / \mathrm{m}^{3} \mathrm{NaOH} a q$. for $12 \mathrm{~h}$ to make the $\mathrm{Na}^{+}$form. The membrane was then soaked in $\mathrm{HCl} a q$. for $24 \mathrm{~h}$ for to make the $\mathrm{H}^{+}$form. The membrane surface was rapidly cleaned with water, and it was soaked in $1 \mathrm{kmol} / \mathrm{m}^{3} \mathrm{NaCl}$ aq. for $12 \mathrm{~h}$ to leach out the $\mathrm{H}^{+}$. The solution was neutralized by titration with $\mathrm{NaOH} a q$, and the ion exchange capacity was calculated.

\subsection{Water content}

The water content $W$ is calculated using the following equation,

$$
W=\frac{W_{1}-W_{2}}{W_{2}} \times 100
$$

where $W_{1}$ and $W_{2}$ are the weights of the wet membranes and dry membranes, respectively.

\subsection{Proton conductivity}

Figure 1 shows the conductance cell used to measure the proton conductivity of the membrane. The cell was filled with $0.5 \mathrm{kmol} / \mathrm{m}^{3} \mathrm{H}_{2} \mathrm{SO}_{4}$ solution. An alternate current of $1 \mathrm{kHz}$ frequency and $0.1 \mathrm{~V}$ amplitude was applied [13]. The distance between the two platinum electrodes (the electrode area: $7.85 \times 10^{-5} \mathrm{~m}^{2}$ ) was fixed $(10 \mathrm{~mm})$, then the proton conductivity $\kappa$ was calculated using equation 2 and equation 3 .

$$
\begin{aligned}
& \Delta R=R_{1}-R_{2}=\frac{L}{A}\left(\frac{1}{\kappa_{0}}-\frac{1}{\kappa}\right) \\
& \kappa=\left(\frac{1}{\kappa_{0}}-\frac{A \Delta R}{L}\right)^{-1}
\end{aligned}
$$

where $R_{1}$ and $R_{2}$ are the resistances under the condition of the membrane not placed in the cell and placed in the cell, respectively, $\kappa_{0}$ is the conductivity of the solution, $A$ 
is the effective membrane area, and $L$ is the thickness of the membrane.

All mesurements were performed at room temperature except tensile tests.

\section{Results and Discussion}

The maximum stress was defined as the upper limit of the stress when the sheet was broken. Figure 2 shows the relationship between the maximum stress and the heating temperature for the original PTFE sheet. The sheet heated at $320^{\circ} \mathrm{C}$ had a maximum stress peak. The sheet was reinforced by melting points crossed with fibers. The melting point of PTFE is $327^{\circ} \mathrm{C}$, and the stress resulted in a decrease down above $320^{\circ} \mathrm{C}$.

The relationships between the stress and the strain of membranes prepared in this study and commercially-available membranes are shown in Fig. 3 and Fig. 4. As can be seen, the PN1 membrane had its

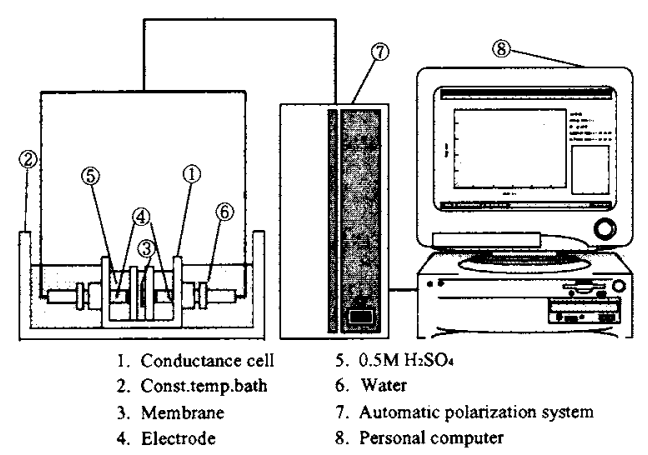

Fig. 1 Schematic diagram of conductance cell.

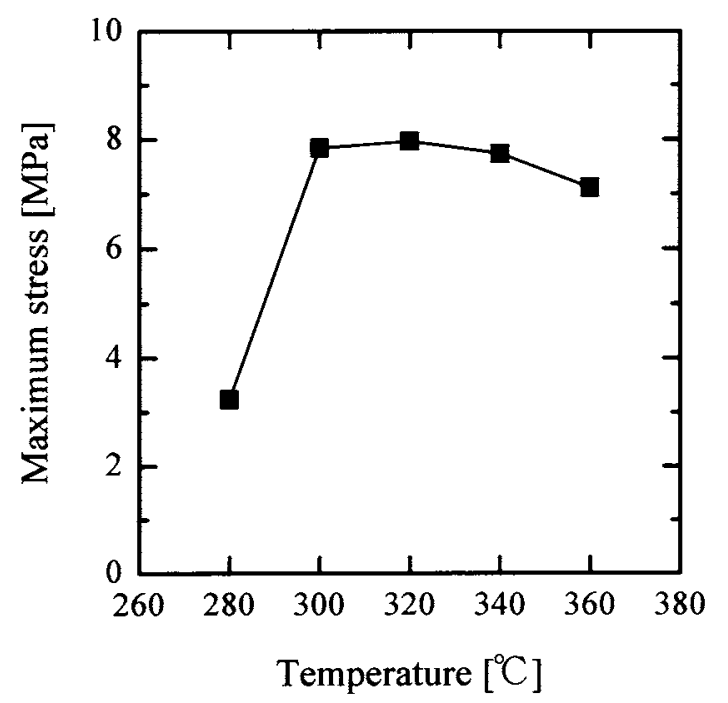

Fig. 2 Relationships between maximum stress and temperature for the original PTFE sheet. highest stress of $27 \mathrm{MPa}$ in the MD and $21 \mathrm{MPa}$ in the TD. The desirable stress of the membrane for fuel cell use is estimated to be above $20 \mathrm{MPa}$ [8]. The PN1 membrane was found to have a stress in excess of 20 $\mathrm{MPa}$ in both directions. The PN1 membrane showed the stress of 1.3 times of a recast membrane in the MD. From this result, it was confirmed that the PN1 membrane was reinforced with the PTFE sheet. The PN2 membrane showed the higher stress of $37 \mathrm{MPa}$ in the MD. However, the PN2 membrane did not approach the desired stress in the TD. The difference in the directivity of the sheet was significantly observed.

Figure 5 shows the relationships between the yield stress and temperature of the hot-pressing treatment of

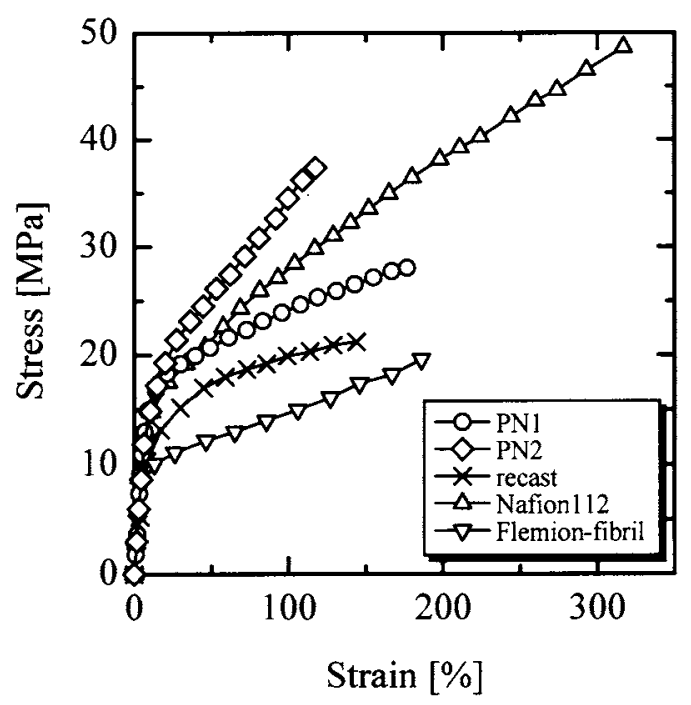

Fig.3 Relationship between stress and strain of ion exchange membranes in the MD.

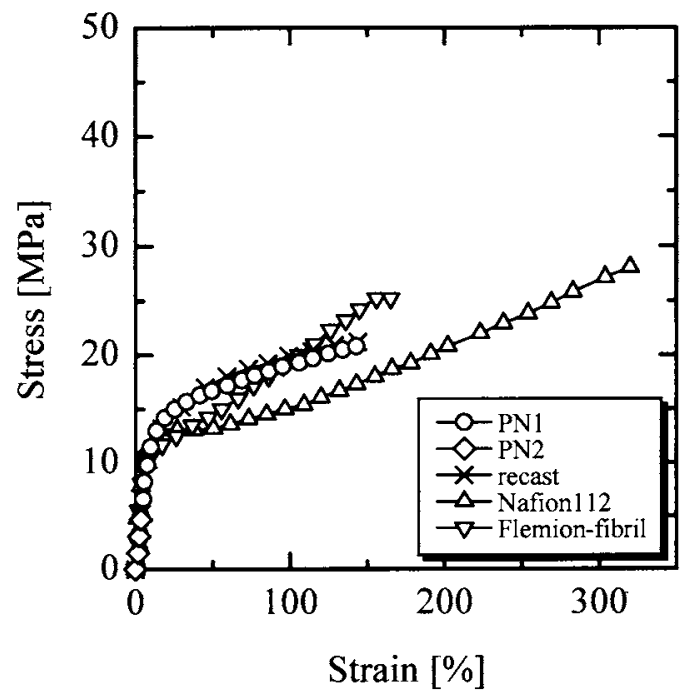

Fig.4 Relationships between stress and strain of ion exchange membranes in the TD. 


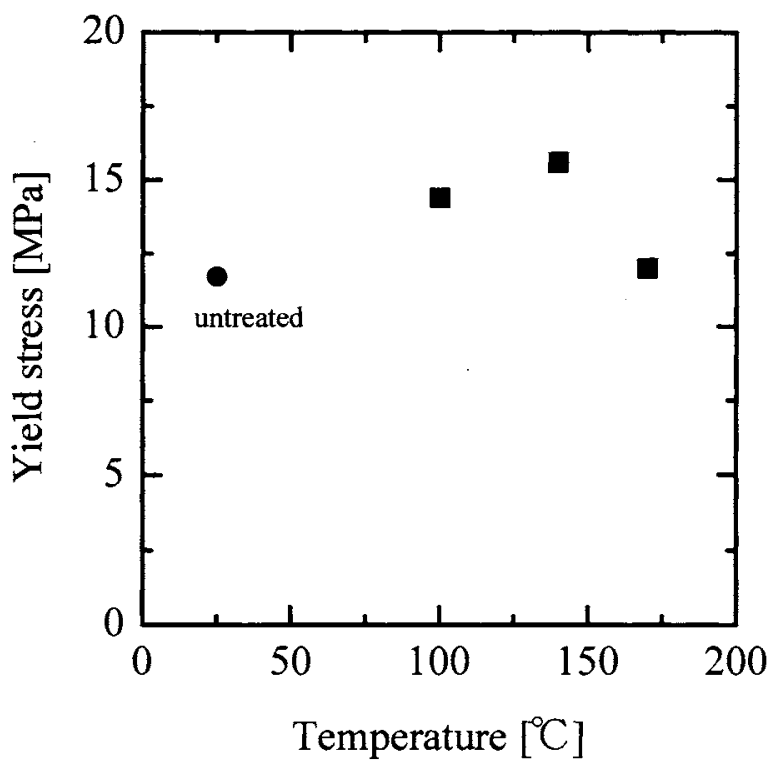

Fig.5 Dependence of temperature on yield stress for recast membrane.

the recast membrane. The recast membrane treated at $140{ }^{\circ} \mathrm{C}$ showed the highest yield stress. Compared between the membrane heat-treated at $140^{\circ} \mathrm{C}$ and the untreated membrane, the treated membrane showed stress 1.3 times that of the untreated membrane.

Table 1 shows the experimental results of the membrane properties. The values of the Flemion-fibril membrane were quoted for comparison [9]. The tensile yield stress of the PN1 membrane was almost equivalent to that of the Nafion 112 in both directions. The tensile yield stress of the PN1 membrane was equal in both directions.

A perfluorosulfonic-acid membrane, such as Nafion, forms ion-cluster channels, and protons conduct under the water-retaining condition [14]. Thus, a high water content is desirable for a perfluorosulfonic-acid based membrane. However, the water content of the PN1 membrane was less than that of the recast membrane, because the PTFE sheet is hydrophobic. The decreasing ratio of the water content was $28.3 \%$, which was equivalent to $28.2 \%$ of the PTFE content in the membrane. The proton conductivity of PN1 decreased about $20 \%$ of that of the recast membrane or Nafion 112 . The ion exchange capacity of PN1 membrane declined more than that of the recast membrane. The PN1 membrane contains the inert polymer of PTFE. There is no $\mathrm{SO}^{3-}$ in the PTFE polymer. However, the reduction ratio of the ion exchange capacity is as low as $7.3 \%$. Both the proton conductivity and the ion exchange capacity of PN membrane were lower than those of the recast membrane, but in case of using porous PTFE membrane water content decreased about $20 \%$ at room temperature [15]. For the Nafion-inorganic composite membrane, the proton conductivity was reduced about $20 \%$ below $50{ }^{\circ} \mathrm{C}$ [16]. Considering the higher tensile yield stress, the PN membrane seemed to be a balanced membrane.

\section{Conclusion}

Novel membranes reinforced with a PTFE sheet for a PEFC were evaluated. By pretreating the sheet at $320^{\circ} \mathrm{C}$ and hot-pressing the membrane at $140{ }^{\circ} \mathrm{C}$, the stress of the PN1 membrane was $27 \mathrm{MPa}$ in the MD, and $21 \mathrm{MPa}$ in the TD, which was beyond the desired value of $20 \mathrm{MPa}$. The yield stress of the PN1 membrane was almost same as that of Nafion 112 in both directions. The water content, ion exchange capacity and membrane conductivity of the PN1 membrane were lower than those of Nafion 112. The reduction ratio of the ion exchange capacity of PN1 to Nafion 112 is as low as $7.3 \%$.

\section{Nomenclature}

A membrane cross section, $\mathrm{m}^{2}$

$L \quad$ distance between electrodes, $\mathrm{m}$

$R_{1} \quad$ resistance of solution, $\Omega$

$R_{2} \quad$ resistance of membrane and solution, $\Omega$

$\Delta R \quad R_{1}-R_{2}, \Omega$

$W \quad$ water content, $\%$

$W_{1} \quad$ weight of wet membrane, $\mathrm{kg}$

Table 1 Properties of various membranes.

\begin{tabular}{|c|c|c|c|c|c|}
\hline \multirow[t]{2}{*}{ Membrane } & \multicolumn{2}{|c|}{ Tensile stress at yield [MPa] } & \multirow{2}{*}{$\begin{array}{c}\text { Water content } \\
{[\%]}\end{array}$} & \multirow{2}{*}{$\begin{array}{c}\text { Ion exchange capacty } \\
{[\mathrm{mol} / \mathrm{kg}-\mathrm{dry}]}\end{array}$} & \multirow{2}{*}{$\begin{array}{c}\text { Proton conductivity } \\
{[\mathrm{S} / \mathrm{m}]}\end{array}$} \\
\hline & $\mathrm{MD}$ & $\mathrm{TD}$ & & & \\
\hline PN1 & 15.6 & 12 & 21.3 & 0.89 & 6.79 \\
\hline PN2 & 20.8 & 5.26 & 24.4 & 0.90 & 6.34 \\
\hline recast & \multicolumn{2}{|c|}{11.6} & 29.7 & 0.96 & 8.49 \\
\hline Flemion-fibril & \multicolumn{2}{|c|}{10.5} & 30.2 & 1.0 & 11.6 \\
\hline Nafion112 & 14.8 & 12 & 35.0 & 1.0 & 9.54 \\
\hline
\end{tabular}


$W_{2} \quad$ weight of dry membrane, $\mathrm{kg}$

$\kappa_{0} \quad$ ionic conductivity of solution, $\mathrm{S} / \mathrm{m}$

$\kappa \quad$ conductivity of membrane, $\mathrm{S} / \mathrm{m}$

\section{References}

1. W. T. Grubb and L. W. Niedrach, J. Electrochem. Soc., 107, 131 (1960).

2. M. L. Perry and T. F. Fuller, J. Electrochem. Soc., 149, S59 (2002).

3. T. Okada, G. Xie, O. Gorseth, S.Kjelstrup, N. Nakamura and T. Arimura, Electrochimica. Acta., 43, 3741 (1998).

4. T. Okada, G. Xie and M. Meeg, Electrochimica. Acta., 43, 2141 (1998).

5. M. Sudoh, T. Fuse, D. Takasu and K. Takuwa, Sen' $i$ Gakkaishi, 52, 110-115 (1996)

6. T. Shimohira and H. Miyake, Nippon Ion Koukan Gakkaishi (in Japanese), 6, 61 (1995).

7. J. S. Jiang, D. B. Greenberg and J. R. Fried, J. Membr.
Sci, 132, 273 (1997).

8. H. Katoh and I. Komada, Jpn. Kokai Tokkyo Koho (in Japanese), H05-75835 (1993).

9. M. Yoshitake, E. Yanagisawa, N. Yoshida, I. Terada, T. Nagamura, T. Ishisaki and Y. Kunisa, Asahi Garasu Kenkyu Houkoku, 50, 67 (2000).

10.T. Suzuki, K. Isobe and H. Shimizu, Jpn. Kokai Tokkyo Koho (in Japanese), S63-165598 (1988).

11.G. Komiyama, T. Suzuki and K. Isobe, Jpn. Kokai Tokkyo Koho (in Japanese), H03-130496 (1991).

12. M. Tanigaki and Y. Okuda, MEMBRANE (in Japanese), 26, 141 (2001).

13.M. Sudoh and J. Yamamoto, Bull. Soc. Sea Water Sci. Jpn. (in Japanese), 49, 341 (1995).

14.T. D. Gierke, G. E. Munn and F. C. Wilson, J. Polym. Sci., 19, 1687 (1981).

15.J. Shim, H. Y. Ha, S. A. Hong and I. H. Oh, J. Power Sources, 109412 (2002).

16.C. Yang, P. Costamagna, S. Srinivasan, J. Benziger, and A.B. Bocarsly, J. Power Sources, 103, I (2001). 